\title{
La genealogía de los niños de la calle y su educación en los Centros de Internamiento en México*
}

\author{
LADISLAO ADRIÁN REYES ${ }^{* *}$ \\ Universidad Autónoma del Estado de Morelos, México. \\ JUAN DE DIOS GONZÁLEZ ${ }^{* * *}$ \\ Universidad Autónoma del Estado de Morelos, México.
}

\section{Primera versión recibida noviembre 4 de 2009; versión final aceptada julio 30 de 2010 (Eds.)}

- Resumen: Los niños y niñas de la calle y en la calle no sólo enfrentan problemas en la sociedad, sino también dentro de las instituciones que los controlan punitivamente. Los hoy llamados Centros de Internamiento han sido parte de diversas instancias gubernamentales, las cuales aplican a los niños y niñas programas educativos paliativos. Actualmente, los niños y niñas son llamados adolescentes para poder ser juzgados como sujetos adultos. El problema de los sujetos menores "delincuentes" no es problema de justicia, es un problema de educación; para tal fin debe hacerse cargo una institución educativa que tenga la infraestructura y los recursos pedagógicos para atenderlos.

Palabras clave: Menores, educación, infractor, justicia, internamiento.

\section{A genealogía dos meninos da rua e sua educaçáo nos internatos de México}

- Resumo: As meninos e meninas abandonados nas ruas não somente enfrentam os problemas na sociedade como também dentro das instituiçóes que as controlam com castigos. Atualmente os chamados internatos, em diferentes escalas públicas aplicam castigos sos meninos e meninas.

Atualmente também as meninas e meninos são considerados adolescentes para poder serem julgados como adultos. O problema dos menores "delinquentes" não é um problema da justiça, é um problema da educação; para solucionar o problema se recomenda una instituiçáo educativa com infraestructura e recursos pedagógicos adequados para atender-los.

Palavras-chave: menores, educação, infrator, justiça, internato.

\section{The genealogy of street children and their education in detention centers in Mexico}

- Abstract: Street children not only face problems in society, but also within the institutions that control punishes. The called Detention Centers have been part of various government bodies which apply only to children hospice programs for their training. Currently, children are called adolescents to be able to be tried as adults. The problem of "criminals" children is not justice problem is a problem of education, for such purpose should be charge the Secretariat of Public Education that has human infrastructure and educational resources to address them.

Keywords: Children, education, lawbreaker, justice, internment.

-1. Introducción. -2. El marco legal de los niños y niñas. -3. De lo educativo a lo punitivo de los

Esta es una investigación financiada con Fondos de Mejoramiento Profesional, Universidad Autónoma del Estado de Morelos, Estados Unidos Mexicanos. Contrato. Promep/103.5/10/ 4590. Área: Seguridad social y grupos vulnerables. Deseamos agradecer la valiosa labor anónima de los evaluadores y evaluadoras.

... Doctor en Administración Pública. Correo electrónico: ladislao.reyes@uaem.mx

*** Doctor en Ciencia Política. Correo electrónico: jdgiba@correo.xoc.uam.mx 
niños y niñas de la calle y en la calle. -4. La Secretaría de Justicia y la Escuela Correccional. -5. La Administración de Justicia de Menores: una realidad. -6. Los programas educativos en el Centro de Atención Especial “Dr. Alfonso Quiroz Cuarón”: Una prisión de menores. -7. Reflexiones finales. -Fuentes documentales primarias y secundarias. -Lista de referencias.

\section{Introducción}

La multiplicidad de problemas que configuran la administración educativa del sujeto menor infractor en los Estados Unidos Mexicanos, constituye un vasto tema de estudio que está reclamando mayores acercamientos analíticos desde los distintos campos del conocimiento. Los incipientes esfuerzos de interpretación, a los cuales se suma este trabajo de investigación, requieren ser sustancialmente incrementados si se desea mejorar, en algún sentido, la compleja situación que se vive en el país en materia de administración educativa de los sujetos menores infractores. El propósito central de este trabajo es comprender la dinámica del sistema punitivo actual, realizando un recorrido histórico crítico de este sector problemático para llegar a reflexiones finales orientadoras al respecto.

Son escasos los estudios sobre el procesoeducativo de los sujetos menores infractores. Quizá debido a que a los sujetos menores problemáticos los atiende la Secretaría de Seguridad Pública, instancia que no es objeto de estudio de los científicos y científicas sociales. Incluso la Secretaría de Educación Pública (SEP) tiene escaso poder de decisión sobre el proceso educativo de los menores. La SEP es una parte accesoria que contribuye en la educación de estos sujetos menores. Las Escuelas Correccionales o reformatorios en México históricamente pertenecían al ramo de la educación, pero debido a circunstancias administrativas perversas ahora son parte del sistema penal.

Las escuelas correccionales han pervertido sus fines educativos y se han convertido en prisiones, llamados actualmente Centros de Tratamiento, como si estos menores fueran enfermos y no menores que deben recibir educación. El problema de los sujetos menores infractores con la reciente reforma al artículo 18 de la Constitución Politica de los Estados Unidos Mexicanos se agudizó, debido a que se reformó el órgano jurisdiccional y no se modificaron los lugares donde se recluye a los sujetos menores, lugares que constituyen verdaderas prisiones con diferentes nombres pero con los mismos defectos y carencias.

\section{El marco legal de los niños y niñas}

Para comprender la problemática actual de los sujetos menores conviene historiar al respecto, considerando conceptualmente la historia como el diálogo que establece el presente con el pasado para construir un mejor futuro, si consideramos la teoría de los ciclos históricos, que en sentido amplio plantea que la realidad actual puede comprenderse por etapas de corta y larga duración, en donde la crisis del derecho es "un lugar común entre juristas, historiadores y filósofos del derecho (Pampillo, 2008, p. 2). En este sentido, en este trabajo intentamos realizar un recorrido histórico de los niños y nińas de la calle y en la calle en los centros de internamiento de los Estados Unidos Mexicanos. Existen diversas disposiciones legales que estipulan la obligación del Estado para darle al niño o niña educación, vivienda, salud y sano esparcimiento, como la Convención Sobre los Derechos del Niño, Las Reglas Minimas de las Naciones Unidas para la Administración de Justicia de Menores, las "Reglas de Beijing", las Reglas de las Naciones Unidas para la Protección de los Menores Privados de su Libertad, los párrafos sexto y séptimo del artículo $4^{\mathrm{o}}$ de la Constitución Política de los Estados Unidos Mexicanos. Las disposiciones anteriores establecen que los niños y niñas tienen derecho a recibir un trato digno, alimentación, salud, educación y sano esparcimiento para su desarrollo integral; que los ascendientes, tutores y custodios tienen el deber de preservar estos derechos, y que el Estado proveerá lo necesario para propiciar el respeto a la dignidad de la niñez y el ejercicio pleno de sus derechos. Las condiciones de encierro a las que son sometidos los sujetos menores internos en instalaciones similares a los centros de reclusión para personas adultas, y la falta de áreas para desarrollar adecuadamente sus actividades educativas, indispensables para la aplicación del tratamiento necesario para su adaptación social, violan todas las disposiciones legales de los niños y niñas. 


\section{De lo educativo a lo punitivo de los niños y nińas de la calle y en la calle.}

Las primeras disposiciones formales que trataron de controlar socialmente las conductas del sujeto menor en México se remontan al año de 1825; en ellas, se establecía implícitamente que la educación de los menores y las menores estaba a cargo de la familia y de los profesores y profesoras. Así, el bando de policía y buen gobierno de 7 de febrero de 1825 instituyó en su numeral 18 que:

También se le exigirá irremisiblemente o se le dará un destino correccional por el alcalde o regidor del cuartel, a cualquier persona de ambos sexos que contra las reglas del pudor y la decencia, se ensuciare en las calles, plazuelas y parajes públicos, como también contra el que en ellos pusiere o derramare vasos de inmundicia; haciéndose extensiva esta providencia a los padres de familia y maestros o maestras de escuelas o amigas, que no impidan a los niños salgan a ensuciarse en las calles, por cuyo descuido se les hace responsables, y sufrirán la exacción de la misma multa (Dublan \& Lozano (s/f), p. 766).

Estas disposiciones tenían poco uso práctico en un ambiente de guerra (Cosío, 1998, p. 101); los dirigentes casi nunca se ocuparon de la eficiencia y del funcionamiento de las instituciones administrativas, su interés se centraba en la política. El gobierno se concretaba a ser un observador y dejaba al libre albedrío de los padres y madres y de los escasos profesores y profesoras la educación de los niños y niñas. Quien asumía la responsabilidad de las infracciones cometidas por los sujetos menores contra otras personas, era la familia o lo eran los tutores en los tribunales.

En marzo del año de 1828 , se creó el primer tribunal que se hacía cargo de las infracciones de los sujetos menores. El código penal tipificaba delitos de menores y sancionaba las conductas antisociales, como la vagancia y las faltas a la "moral" cometidas por los niños y niñas de la calle y en la calle. Este órgano jurisdiccional administrativo estaba presidido por un alcalde y dos regidores adjuntos, que sesionaban los lunes y jueves. El proceso para juzgar al nińo o niña se llevaba a cabo en una sala especial llamada "Sala Capitular" y, por lo general, eran procesos privados. El órgano jurisdiccional se llamaba Tribunales de vagos en el distrito y territorios, y declaraba como vagos y viciosos:

I. A los que sin oficio ni beneficio, hacienda o renta viven sin saber de qué les venga la subsistencia por medios lícitos y honestos.

II. El que teniendo algún patrimonio o emolumento o siendo hijo de familia no se le conoce otro empleo que el de las casas de juego, compañías mal opinadas, frecuencia de parajes sospechosos y ninguna demostración de emprender destino en su esfera.

III. El que vigoroso, sano, robusto en edad y aún con lesión que no le impida ejercer algún oficio, solo se mantiene de pedir limosna.

IV. El hijo de familia que mal inclinado no sirve en casa y en el pueblo de otra cosa que escandalizar con la poca reverencia $u$ obediencia a sus padres, y con el ejercicio de las malas costumbres, sin propensión o aplicación a la carrera que le ponen.

VII. Estas malas cualidades se deberán justificar con información sumaria, con citación del sindico del ayuntamiento para que haga las veces de promotor fiscal.

XIX. Habiendo semiplena prueba o indicio de que alguno es vago, u ocioso, se procederá a su aprehensión y se pondrá en la cárcel en el departamento de los detenidos.

XIV. Los que fueren declarados vagos por el tribunal, serán destinados al servicio de las armas, o a la marina, o a la colonización, o a casas de corrección.

XV. Los impedidos para trabajar, o los muchachos dispersos que no hayan llegado a la edad de 16 años, serán puestos en casas de corrección, o a falta de éstas se pondrá a los últimos, a aprender oficio, bajo el gobierno y dirección de maestros que sean de la satisfacción de autoridad política (Dublán \& Lozano (s/f), p. 766).

Los Tribunales de vagos en el distrito y territorios fueron el antecedente de los tribunales de los niños y niñas de la calle y en la calle; este tribunal era similar, jurídicamente, a un promotorfiscal, persona que realizaba las tareas de un "Juez paternal". La vagancia (Soberanes, 1997, p. 70) era uno de los 
múltiples delitos que perseguía la administración de justicia de menores y, por lo general, no existían casas de corrección, como se puede apreciar en los bandos que emitía la administración pública. El lugar donde se recluía al sujeto menor era la prisión. En ciertos casos los hospicios servían como prisiones alternas donde los menores y las menores purgaban la pena, los cuales tenían la finalidad de inmovilizar al niño o niña. La organización de la prisión era rudimentaria y en nada se parecía al panóptico (Bentham, 1979, p. 125), que buscaba readaptar al niño o niña que delinquía. Sin embargo, el tribunal que sancionaba a los niños y niñas en el Distrito Federal y territorios nunca operó plenamente.

\section{La Secretaría de Justicia y la Escuela Correccional.}

La original Secretaría de Estado y del Despacho de Relaciones Interiores y Exteriores que se ocupó de los sujetos menores de la calle se fue dividiendo en múltiples secretarías. Posteriormente, con la formación de la Secretaría de Justicia e Instrucción Pública, los menores y las menores de la calle quedaron bajo su tutela y quienes eran antisociales fueron recluidos en prisiones de gente adulta.

Las condiciones infrahumanas de los sujetos menores en prisión fueron percibidas por diferentes personas preocupadas por su condición (Soberanes, 1997 , p. 57). Para mejorar las condiciones de los menores y de las menores en el año de 1841, Don Manuel Eduardo Gorostiza estableció una casa correccional anexa al Hospital de Pobres, con fondos de la administración municipal. En el año de 1861, siendo presidente de la República Benito Juárez y Ministro de Instrucción Pública, Ignacio Ramírez, el Ayuntamiento de Tepeaca, Puebla, regaló un edificio para establecer una casa de corrección y una escuela de artes, que nunca se estableció.

El 7 de diciembre del año de 1871, el Congreso expidió un Código Penal referente a los niños. En el artículo 13 de su ley transitoria, ordenaba que los establecimientos conocidos con los nombres de Tecpan de Santiago (Del Castillo, 1994, p. 388) y Hospicio de Pobres, fuesen destinados para la corrección penal y para la educación correccional de los jóvenes delincuentes (Soberanes, 1997, p. 304). Formalmente, desde esta fecha a los menores infractores se les ubicó en el sistema penal. En ese colegio, se les internaba para su reeducación. Los niños que cometían delitos graves eran llevados a la prisión de Belén.

Se cuenta que los carceleros sintieron lástima por los menores y los segregaron en una crujía especial, "dándoles uniformes verdes para distinguirlos y controlarlos mejor, razón por la cual se le llamó 'Crujía de los Pericos'. Esta cárcel fue calculada para 800 varones y 400 menores (Marín, 1999, p. 21)”. Así, de manera general, la Administración Educativa de Menores estaba pésimamente organizada; sólo era una forma de control administrativo. La Administración educativa y la Administración de justicia que atendía a los menores infractores, no sólo era deficiente para la reeducación de los menores, sino que también arrastraba grandes problemas de presupuesto y el ineficiente sistema penitenciario (Soberanes, 1997, p. 71).

Hasta ese momento, las escasas instituciones que creó el gobierno para educar y reeducar a los menores estaban a cargo de la Secretaría de Justicia e Instrucción Pública. La preocupación por crear una institución capaz de atender al menor era patente, ya que las consignaciones aumentaban; así se nota, que

(...) durante el indicado año de 1892, aumentó el número de consignaciones en 630 respecto de 1891; el de personas consignadas en 740; el de menores de edad en 5166; el de solteros en 1015; el de las personas que no tenían oficio en 1523; el de los sujetos que no sabían leer ni escribir en 1236, y el de los que estaban ebrios en 342; pudiéndose precisar de estos datos que el mayor número de delincuentes eran los menores de edad (Soberanes, 1997, p. 421).

La multiplicidad de tareas encomendadas a la Secretaría de Justicia e Instrucción Pública no permitió que se hiciera más eficiente y eficaz su funcionamiento. Para ello se decretó, el 16 de mayo de 1905, que el ramo de la Instrucción Pública fuese separado de la Secretaría de Justicia (Instituto Nacional de Administración Pública, 1999, p. 11). Esta división administrativa tuvo como finalidad atender con mayor eficacia $y$ eficiencia cada uno de los rubros de la formación de los sujetos menores. Sin embargo, las instituciones a cargo de los sujetos menores problemáticos fueron asignadas a la Secretaría de Justicia y no a la Secretaría de Instrucción Pública, que era el lugar 
que le correspondía por ser menores en formación. Las razones no se encuentran inventariadas, pero suponemos que los menores y las menores que infringían una disposición no eran percibidos como niños o niñas normales que estaban en proceso de educación.

Desde aquella época los sujetos menores infractores se consideraron delincuentes. No se les contempló como sujetos que se están formando y queson susceptibles decambiar su comportamiento. Consideramos que es la educación la que debe generar un proceso capaz de crear potencialidades en el niño, niña o adolescente, para ser personas útiles a sí mismos y a la sociedad. A pesar de que existía la preocupación en los titulares de la Secretaría de Justicia, nunca se concretó un proyecto para crear una institución educativa para los sujetos menores.

\section{La Administración de Justicia de Menores: una realidad}

El 30 de septiembre de 1908 (Ceniceros, 1936, p. 19) el Gobierno del Distrito Federal le plantea a la Secretaría de Estado y Despacho de Gobernación reformar las leyes que se aplicaban al sujeto menor para mejorar sus condiciones de vida. Por medio de un oficio, propone un Proyecto de Reformas a la Legislación Penal.

En el proyecto, el gobierno del Distrito Federal, da cuenta de las gestiones que con anterioridad había dirigido a la Secretaría de Justicia para la creación del órgano jurisdiccional de menores. La petición no fue contestada, lo que motivó que se dirigiera a la Secretaría de Despacho y Gobernación. Resalta en el oficio que el establecimiento que funciona con el nombre de Escuela Correccional de Artes y Oficios para Varones, no se sujeta a los requisitos que el derecho penal prescribe, por lo cual, "la escuela Correccional no es otra cosa que una cárcel con todos los defectos de que vienen adoleciendo los establecimientos de esta especie, desde que la Nueva Espańa se independizó de la metrópoli (Ceniceros, 1936, p. 19)".

El gobierno del Distrito Federal explica en el proyecto, que en la Escuela Correccional se encuentran menores que no son delincuentes; es decir, existen niños y niñas menores recluidos, abandonados por sus padres y madres, que al contacto con sujetos criminales siguen los pasos de éstos, por lo cual es necesario tomar medidas preventivas mientras se concluye la construcción del edificio que se está llevando a cabo en la Cabecera de la municipalidad de Tlalpan.

Asimismo, el gobierno del Distrito Federal gira un oficio a la Secretaría de Despacho y Gobernación para que los Comisarios de policía no lleven niños y niñas a la Escuela Correccional por peleas simples, por robos insignificantes o que hayan delinquido por primera vez; los niños y nińas de la calle y en la calle, en estos supuestos deben ser entregados a sus padres y madres o a las instituciones que los eduquen. Se indica que los niños y niñas abandonados o menores de 14 años sean llevados a un hospicio y no a la Escuela Correccional.

Antela inactividad de la Secretaría de Despachoy Gobernación y la Secretaría de Justicia para resolver la problemática del sujeto menor, el gobierno del Distrito Federal decidió construir un sitio en el que pudiera retener y controlar socialmente a los menores de edad. Por ello, en La Gaceta del año IV, Tomo II, de la Ciudad de México, del 25 de octubre de 1908, se describe la estructura de la nueva organización administrativa, donde además se puntualiza el mal funcionamiento del antiguo lugar de reclusión de menores:

El jueves de la semana próxima pasada fueron trasladados (sic) al nuevo edificio, que en Tlalpan se ha destinado (sic) a Escuela correccional para Menores, los que ocuparon (sic) por mucho tiempo el edificio del ExConvento de San Pedro y San Pablo, que a pesar de las reformas que se le hicieron hace 10 ańos era poco adecuado para su objetivo, por razón de su vestutez (sic) y de hallarse en el centro de la ciudad, donde por razón natural al aire que se respira está viciado por la misma ciudad.

Estas razones, y otras de disciplina, hicieron que se pensara trasladar la escuela a un lugar que se encontrara en el campo y que reuniera las necesidades ( $s i c$ ), condiciones de amplitud y aislamiento. Éstas se hallaron en un terreno situado en las cercanías del pueblo de Tlalpan, a un lado de la vía de tranvías de tracción animal que va de la estación a la Escuela de aspirantes (sic). El terreno mide $40,000 \mathrm{~m}^{2}$ de superficie, la mayor parte de los cuales se dedican al cultivo de plantas (sic) y legumbres, lo que al mismo tiempo que servirá útil 
solaz (sic) a los corrigendos (sic), les hará tornar cariño por la tierra, pasión muy poco desarrollada por las personas que se educan en el medio ambiente de nuestra ciudad. En el centro de este extenso terreno se construyó el edificio nuevo desde sus cimientos (sic) y bastante amplio para contener el doble o más de los corrientes confinados actualmente en la escuela. La distribución que se ha dado al edificio responde perfectamente a las exigencias de la moderna educación penal. Las dependencias de que consta, están distribuidas en dos pisos, en el primero están los talleres y las aulas de clases; estas últimas son de orfeón, de orquesta y de banda y las necesarias para impartir a los reclusos la instrucción primaria, elemental y superior. En la planta alta hay ocho salones, dormitorios grandes y bien ventilados y dos más pequeños que se dedican a enfermería y servicio médico, éste cuenta además con departamentos para botiquín, cuarto de practicantes y demás dependencias necesarias para un servicio médico completo. El director de la Escuela, Capitán A. Sotelo, ha tenido cuidado que todos los departamentos sean amplios y acondicionados, los talleres están en salones que miden $25 \mathrm{~m}$ de largo por 6 de ancho y reciben sol y aire por numerosas ventanas. Para facilitar el despacho de asuntos que se relacionan con las causas judiciales que siguen a los corrigendos, se ha instalado en el edificio de la Escuela una oficina dependiente del juzgado de Tlalpan en la que se tramitan hasta donde sean posibles todas las causas de los reclusos[...] (Marín, 1991, p. 27).

La Escuela Correccional de Tlalpan se convirtió en un control de niños y niñas centralizado; ahí se recluía a los niños infractores del Distrito Federal y de otros estados de la Federación, lo que muy pronto generó hacinamiento. Con motivo del traslado a Tlalpan de la Escuela Correccional para delincuentes varones menores de edad y a la Escuela Correccional para mujeres en Coyoacán, fue necesario dictar algunas disposiciones que facilitasen la práctica de diligencias judiciales con los menores procesados y recluidos en los mencionados establecimientos; y para tal efecto, se expidió la circular número 181 , del $1^{\circ}$ de marzo de 1908 (documento número 124) que en lo sustancial previene: 1o. que cuando los Tribunales del Distrito Federal tengan que practicar diligencias con menores recluidos en establecimientos de corrección penal, lo hagan por medio de orden o exhorto, según sea la categoría del tribunal, dirigido al juez de Tlalpan, si se trataba (sic) de menores varones o al de Coyoacán si se trata de menores mujeres; 2o. que cuando las diligencias requieran precisamente la presencia del menor y no puedan desahogarse por medio de exhorto, pidan la comparecencia por conducto del Gobierno del Distrito y señalen para la diligencia los lunes o jueves de cada semana; y 3o. que dichos tribunales no difieran ni demoren la verificación de esas diligencias una vez señaladas, a fin de evitar (sic) que los menores puedan regresar a su establecimiento a hora reglamentaria, y que los agentes de policía no pierdan el tiempo inútilmente en la conducción y custodia de dichos menores (Marín, 1999, p. 27).

En el mismo sentido, se buscó que fueran jueces cercanos quienes juzgaran a los niños y niñas para evitar que fueran maltratados en su traslado de grandes distancias. Para evitar que los sujetos menores fueran vejados se emitió la circular

(...) número 189 expedida el 7 de Enero de 1910, que obliga a los Jueces del ramo penal del Distrito Federal en los procesos que instruyan contra menores delincuentes, recluidos en Establecimientos de Corrección Penal y que estén situados fuera de su jurisdicción, encomienden la práctica de esas diligencias al juez bajo cuya jurisdicción se encuentra la Escuela Correccional (Marín, 1999, p. 520).

En 1917, por lo que respecta a la Secretaría de Justicia (Cpeum, 2008, art.136), se dispuso que sus funciones fueran absorbidas por un Departamento Judicial y la Secretaría de Gobernación. Por ello, por Decreto del $1^{\circ}$ de mayo de 1917 se sumaron a la Secretaría de Estado los negocios que habían pertenecido a la Secretaría de Justicia, y las instituciones especiales para el tratamiento de los niños y nińas infractores quedaron a cargo del Gobierno del Distrito Federal.

A partir del año de 1917, el sistema que atiende a los sujetos menores infractores ha pasado por diferentes Secretarías, como la 
Secretaría de Gobernación. Actualmente se rige bajo los lineamientos de la Secretaría de Seguridad Pública. Las políticas para adaptar, reeducar, o formar, no han cambiado sustancialmente. La Escuela Correccional o Reformatorio, los Centros de Tratamiento - hoy llamados Centros de internamiento- siguen siendo prisiones donde la educación aún es un elemento represivo que no ayuda en la mejor formación.

\section{Los programas educativos en el Centro de Atención Especial "Dr. Alfonso Quiroz Cuarón”: Una prisión de menores}

Actualmente muchos niños y niñas de la calle y en la calle, debido a múltiples factores, se encuentran en los Centros de internamiento por haber cometido conductas tipificadas en el Código Penal. Los Centros de internamiento son las prisiones de los niños y niñas. Son prisiones, en el sentido más estricto, que tienen programas de educación anquilosados. El Centro de internamiento de San Fernando se encuentra en Tlalpan, Distrito Federal. El otro centro de internamiento de menores se llama Centro de Atención Especial "Dr. Alfonso Quiroz Cuarón”. Es una prisión de alta seguridad para niños que se fundó en 1990 (Reyes, 2007b, p. 169) (Recomendación 90/97, 1997, p. 156).

En el Centro de Atención Especial "Dr. Alfonso Quiroz Cuarón," se recluye en celdas a los menores infractores que son trasladados de otros Centros de Tratamiento por llevar a cabo conductas graves contra otros compañeros o con el personal de la institución; específicamente por la alta agresividad, reincidencia, alteraciones importantes del comportamiento o conductas que alteren gravemente el orden del Centro de internamiento de Tlalpan.

La capacidad de internamiento del Centro de Atención Especial "Dr. Alfonso Quiroz Cuarón" es de veinticuatro menores. Es una población pequeña, pero ello no significa mejor trato o atención. El Centro ocupa una superficie aproximada de 2,326 metros cuadrados. Consta de tres dormitorios, dos módulos de seguridad, área de gobierno, dos patios con una cancha deportiva, aduana de personas, área de calderas y estacionamiento. Cada dormitorio tiene un pasillo central, a un lado del cual están las celdas y los cubículos (Recomendación 50/97, 1997, p. 1ss).

Cada dormitorio cuenta con ocho celdas individuales de 1.5 metros por dos metros, inferior incluso a las celdas del Centro de Readaptación Social Número 1, en Almoloya de Juárez, que miden alrededor de dos metros por tres metros. Cada celda está provista de una cama, colchón y ropa de cama, una mesa, taza sanitaria revestida de concreto y lavabo. Queda un espacio de alrededor de un metro cuadrado disponible para caminar (Recomendación 50/97, 1997, p. 1ss).

Las celdas tienen tres paredes de concreto y una reja de barrote que da al pasillo central. La puerta de cada celda — también de barrotesestá provista de dos cerraduras, una de la cuales es una chapa manual y la otra opera mediante un sistema electromagnético manejado desde uno de los módulos de control (Recomendación 50/97, 1997, p. 1ss). En cada dormitorio hay un baño de uso común, que genera carencia de privacidad, equipado con lavadero y una regadera que no cuenta con agua caliente, a pesar de que el reglamento del Centro estipula que se debe contar con agua potable para consumo de los menores, con sanitarios higiénicos, regaderas con agua caliente y áreas de descanso.

Los tres cubículos que hay en cada dormitorio, dan por el frente al pasillo central, y por otro lado colindan con el patio por medio de ventanas y puertas con barrotes. En ellos se realizan las actividades técnicas y educativas. Las celdas no tienen ventanas; la luz solar sólo penetra a través de la puerta - proveniente de los cubículos que están al frente y que cuentan con ventanas de vidrioy resulta insuficiente. Las celdas tampoco tienen luz artificial, pero la reciben de las lámparas que están en el pasillo. La ventilación se hace por la puerta de barrotes (Recomendación 50/97, 1997, p. 1ss).

El acceso a todas las áreas se controla con puertas de barrotes, reforzadas con chapas de alta seguridad. Los corredores de los dormitorios tienen doble puerta de barrotes. Es una prisión de alta seguridad, donde se inmoviliza al menor, por lo que su adaptación o educación en esas condiciones es una utopía. Podrán aplicarse los mejores tratamientos pero, en esas condiciones, sus resultados no pueden ser satisfactorios. El edificio es una prisión con jaulas, donde los internos se estresan y adquieren fobias (Observaciones, 2007, 
p. 1ss).

Los tres dormitorios conocidos como A, B, C, corresponden a partes del tratamiento denominadas fases. La fase I es la más severa por lo que respecta a las actividades. En la fase II y III al niño se le conceden derechos y mayor tiempo para que disfrute de ciertos "privilegios" (Recomendación
50/97, 1997, p. 106).

Cuando el menor ingresa al Centro de Atención Especial “Dr. Alfonso Quiroz Cuarón”, es ubicado en la primera etapa, donde permanece un mínimo de seis meses. En la fase primera se realizan las siguientes actividades (Recomendación 50/97, 1997, p. 108):

\section{FASE I}

\begin{tabular}{|l|l|l|}
\hline ACTIVIDAD & PERIODICIDAD & DURACIÓN \\
\hline Deportes & $\begin{array}{l}\text { Dos veces por día } \\
\text { De lunes a sábado }\end{array}$ & 30 minutos \\
\hline Aseo personal & Todos los días & 10 minutos \\
\hline Pedagogía & Lunes a viernes & 1 hora \\
\hline Trabajo social & Lunes a viernes & 1 hora \\
\hline Psicología & Lunes a viernes & 1 hora \\
\hline Psiquiatría & Lunes a viernes & 1 hora \\
\hline Aseo programado & $\begin{array}{l}\text { Una vez por semana, } \\
\text { Tres veces al día }\end{array}$ & 30 minutos \\
\hline Televisión & Sábados & 1 hora \\
\hline Recreativas & $\begin{array}{l}\text { Sábados } \\
\text { Domingos }\end{array}$ & $\begin{array}{l}\text { De } 3 \text { a } 4 \text { horas } \\
5 \text { horas }\end{array}$ \\
\hline Visita familiar & Domingos & 4 horas \\
\hline Visita religiosa & Domingos & 1 hora \\
\hline
\end{tabular}

A pesar de que estos programas intentan mejorar la adaptación del menor, son contradictorios con las declaraciones de los menores, quienes manifiestan que permanecen la mayor parte del tiempo encerrados en sus celdas; incluso desean ser trasladados a un reclusorio de adultos, toda vez que tantas horas de encierro provocan en el niño desesperación (Recomendación 50/97, 1997, p. 108). Las suspensiones de las actividades técnicas son frecuentes, siendo habitual que los menores ni siquiera puedan acudir a las regaderas. El director del Centro expresa que a estos muchachos se les suspenden sus actividades porque "mientan la madre, orinan o arrojan comida al personal" (Recomendación 50/97, 1997, p. 109).

Para cambiar de fase, se requiere una previa determinación del Consejo Técnico
Interdisciplinario. Autorizada la fase II, el tratamiento consta de las actividades mencionadas a continuación en el cuadro siguiente. En esta fase, según observaciones de la Comisión Nacional de Derechos Humanos, existen irregularidades, ya que hay menores que están en fase I y gozan de la fase II, o viceversa (Recomendación 50/97, 1997, p. 106).

Las actividades programadas para la fase II son las que se enlistan enseguida: 


\begin{tabular}{|l|l|l|}
\hline \multicolumn{2}{|c|}{ FASE II } \\
\hline ACTIVIDAD & PERIODICIDAD & DURACIÓN \\
\hline Deportes & Lunes a viernes & 2 horas \\
\hline Aseo personal & Todos los días & 10 minutos \\
\hline Pedagogía & Lunes y viernes & 1 hora \\
\hline Trabajo social & Lunes a viernes & 1 hora \\
\hline Psicología & Lunes a viernes & 1 hora \\
\hline Psiquiatría & Lunes a viernes & 1 hora \\
\hline Aseo de estancia & Sábado, tres veces al día & 30 minutos \\
\hline Televisión & $\begin{array}{l}\text { Lunes a viernes } \\
\text { Sábado }\end{array}$ & $\begin{array}{l}1 \text { hora } \\
2 \text { horas }\end{array}$ \\
\hline Mecanografía & Lunes a viernes & 1 hora \\
\hline
\end{tabular}

La fase III es una etapa en la que se proporcionan mayores estímulos a los menores. Los menores infractores salen en grupo a hacer deporte; tienen permiso para usar televisión, grabadora y equipo de cómputo; participan en actividades dentro del área de gobierno, tienen clases de ajedrez y pueden ser visitados en horarios fuera de lo normal.

Las actividades son:

\section{FASE III}

\begin{tabular}{|l|l|l|}
\hline ACTIVIDAD & PERIODICIDAD & DURACIÓN \\
\hline Deporte & Lunes a viernes & 1 hora \\
\hline Aseo personal & Todos los días & 10 minutos \\
\hline Pedagogía & Lunes a viernes & 1 hora \\
\hline Trabajo social & Lunes a viernes & 1 hora \\
\hline Psicología & Lunes a viernes & 1 hora \\
\hline Psiquiatría & Lunes a viernes & 1 hora \\
\hline Aseo de instancia & Sábado, tres veces al día & 30 minutos \\
\hline Televisión & $\begin{array}{l}\text { Lunes a viernes } \\
\text { Sábado y domingo }\end{array}$ & $\begin{array}{l}2 \text { horas } \\
3 \text { horas }\end{array}$ \\
\hline Mecanografía & Lunes a viernes & 1 hora \\
\hline Recreativas & $\begin{array}{l}\text { Sábado } \\
\text { Domingo a lunes }\end{array}$ & $\begin{array}{l}1 \text { hora } \\
4 \text { horas }\end{array}$ \\
\hline Visita familiar & Domingo & 4 horas \\
\hline Visita religiosa & Domingo & 1 hora \\
\hline Computación & Lunes a viernes & 1 hora \\
\hline
\end{tabular}


El Consejo Técnico del Centro prohíbe cambiar al menor de fase aunque de hecho discrecionalmente lo hacen. El Consejo Técnico del Centro de Atención Especial puede presentar al Comité Técnico Interdisciplinario un rediseño de las medidas de tratamiento, otorgando estímulos o terminando las medidas disciplinarias. En sentido amplio, los cambios de fases se basan en premios y castigos, medidas que no cambian los comportamientos indeseados de los niños.

La ociosidad es uno de los males del Centro, ya que en ninguna de las fases el menor tiene la posibilidad de trabajar, porque se dice por parte de la autoridad que cualquier labor es un peligro para la seguridad del establecimiento. Los servicios de psiquiatría, psicología y trabajo social, que deberían ser permanentes, son retirados si las conductas esperadas no son las adecuadas (Recomendación 50/97, 1997, p. 110).

A pesar de las recomendaciones hechas en el año de 1997 por la Comisión de Derechos Humanos para humanizar el Centro de Internamiento Centro de Atención Especial "Dr. Alfonso Quiroz Cuarón”, la situación lamentablemente persiste, conforme las observaciones que hemos realizado. Lo anterior genera que muchos niños y niñas de la calle y en la calle sigan siendo los huéspedes maltratados de estos Centros de internamiento (Reyes, 2007, p. 178).

La situación tiende a agravarse para estos niños y niñas, ya que los nuevos ordenamientos sacan de contexto la definición de niño o niña. La Convención de los Derechos del niño establece en su artículo 10. "Para los efectos de la presente Convención, se entiende por niño todo ser humano menor de dieciocho años de edad, salvo que, en virtud de la ley que le sea aplicable, haya alcanzado antes la mayoría de edad". Empero, la Ley de justicia para Adolescentes del Distrito Federal, establece un subterfugio legal para juzgar con severidad a los niños y niñas de la calle y en la calle llamándolos adolescentes; así establece en su artículo $2^{\circ}$. Artículo 2. Sujetos. Para los efectos de esta Ley, se entenderá: "I. Adolescente. Persona cuya edad se encuentra comprendida entre los doce años de edad cumplidos y menos de dieciocho años de edad...”. Desaparece la definición de niño o niña y se establece que son adolescentes todos los niños y niñas, y por tanto pueden ser sujetos imputables de delitos. Los niños y niñas ya no son inimputables como lo establece el Código Penal Federal artículo 15 fracción VII y Código Penal del Distrito Federal en sus excluyentes del delito.

Incluso en el artículo $5^{\circ}$ de la Ley de justicia para Adolescentes del Distrito Federal, se plantea que los niños menores de doce años son adolescentes:

Menores de doce años de edad. Las personas menores de doce años de edad que hayan realizado una conducta tipificada como delito en la Ley, sólo serán sujetos de rehabilitación y asistencia social por las instancias especializadas del Distrito Federal. Y no podrá adoptarse medida alguna que implique su privación de libertad. Cuando el agente del Ministerio Público que haya dado inicio a la averiguación Previa se percate que el adolescente es menor de doce años, dará aviso a la Dirección Ejecutiva de Asuntos Jurídicos del Sistema para el Desarrollo Integral de la Familia para el Distrito Federal, donde se tramitará la debida asistencia social en beneficio de la rehabilitación del niño involucrado y, en su caso, de su familia (las negritas son nuestras).

Además, las nuevas reformas utilizan la analogía para tipificar las conductas de los sujetos menores utilizando el Código penal de Adultos para juzgarlos. La Constitución Politica de los Estados Unidos Mexicanos (Cpeum) establece en su artículo 14... "En los juicios del orden criminal queda prohibido imponer, por simple analogía, y aún por mayoría de razón, pena alguna que no esté decretada por una ley exactamente aplicable al delito de que se trata..." Es decir, es inconstitucional que se esté juzgando a los niños y niñas con un Código diseñado para sujetos adultos y estableciendo procesos como si fueran sujetos adultos.

De acuerdo con el artículo 14 de la Cpeum, es menester que exista un Código Penal para adolescentes para que sea legal cualquier detención en una prisión. Además, se establece en la Cpeum que los adolescentes que cometan conductas típicas catalogadas por el Código Penal como graves, serán recluidos en la prisión (Centros de internamiento). Un alto porcentaje de los delitos de los Códigos Penales son considerados graves, lo que actualmente genera que los Centros de internamiento estén saturados provocando motines y escapes.

El problema de los niños y niñas de la calle y en la calle no es un problema de impartición de justicia. Es un problema de educación en virtud 
de que el mismo se origina en el seno familiar y en la falta de suficientes centros educativos de calidad. Los niños y niñas en las calles aprenden una cantidad de conductas tipificadas como delitos, que son reforzadas en estos Centros de Internamiento, donde impera la violencia y la muerte (Recomendación de CNDH, 2006: 1y ss.). La respuesta debe ser una institución educativa que cuente con los recursos humanos, pedagógicos, técnicos y materiales, que capacite a los niños y niñas de la calle para que puedan ser ciudadanos y ciudadanas ejemplares.

\section{Reflexiones finales}

Los Tribunales de vagos en el distrito y territorios, son el antecedente de los tribunales de los niños y niñas de la calle y en la calle. Los padres, las madres, los tutores y tutoras, y los profesores y profesoras, eran responsables solidarios de las conductas antisociales de los niños y niñas, ya que ellos eran los garantes de su educación.

El 16 de mayo de 1905, el ramo de la Instrucción Pública fue separado de la Secretaría de Justicia. A partir de esta fecha los niños problemáticos fueron asignados a la Secretaría de Justicia que construyó en una prisión para menores donde el ocio es parte de la institución.

En 1917 las funciones de la Secretaría de Justicia fueron absorbidas por un Departamento Judicial, y por la Secretaría de Gobernación. Por ello, por Decreto del 10 de mayo de 1917 se sumaron a la Secretaría de Estado los negocios que habían pertenecido a la Secretaría de Justicia, y las instituciones especiales para el tratamiento de los niños infractores quedaron a cargo del Gobierno del Distrito Federal.

A partir del año de 1917, el sistema que atiende a los sujetos menores infractores ha pasado por diferentes Secretarías, como la Secretaría de Gobernación. Actualmente se rigen bajo los lineamientos de la Secretaría de Seguridad Pública. Los Centros de internamiento siguen siendo prisiones donde la educación de los niños y niñas de la calle es aún un elemento paliativo de su formación.

La educación de los niños en la prisión de alta seguridad de menores, llamado Centro de Atención Especial “Dr. Alfonso Quiroz Cuarón”, se basa anacrónicamente en el anti-sistema educativo de premios y castigos. Los castigos son la reclusión en lugares insalubres, y los golpes. Los programas educativos que realizan los niños son paliativos que no sirven para su formación integral, como lo que establecen leyes como la Convención Sobre los Derechos del Niño, Las Reglas Minimas de las Naciones Unidas para la Administración de Justicia de Menores, "Reglas de Beijing", las Reglas de las Naciones Unidas para la Protección de los Menores Privados de su Libertad, y los párrafos sexto y séptimo del artículo 4o. de la Constitución Política de los Estados Unidos Mexicanos.

Tal como lo hemos reiterado, esta investigación busca conocer desde la historia pasada y actual la problemática presente de los niños y niñas de la calle y sus carencias en los Centros de Internamiento; sin embargo, tales aspiraciones están limitadas por la magnitud de los problemas de dicho ámbito y por las involuntarias lagunas del trabajo. En todo caso, lo que podemos afirmar en buena lógica es que la discusión sobre el tema ha de ser realizada de manera seria e impostergable en México. A esa tarea se suma sin vacilación este trabajo, en el que no planteamos posiciones últimas, sino enfoques que pretendemos sumar al necesario esfuerzo colectivo en favor de una mejor vida de los nińos y niñas de la calle y de su permanencia en los Centros de internamiento para ellos y ellas en los Estados Unidos Mexicanos.

\section{Lista de referencias}

Bentham, J. (1979). El Panóptico. Madrid: La Piqueta.

Ceniceros, J. Á. \& Garrido, L. (1936). La delincuencia infantil en México. México, D. F.: Botas.

CNDH (2009). Legislación y Recomendaciones de la Comisión Nacional de Derechos Humanos de México. México, D. F.: CNDH.

Constitución Politica de los Estados Unidos Mexicanos (2010). México, D. F.: Porrúa.

Cosío, D. (1998). Historia minima de México. México, D. F.: Colegio de México.

Diario Oficial de la Federación el 25 de enero de (1991). Convención Sobre los Derechos del Niño. México, D. F.: Gobierno Nacional.

Del Castillo, J. M. (1994). Ensayo sobre el Derecho Administrativo Mexicano. México, D. F.: Unam. 
Dublán, M. \& Lozano, J. M. (s/f) Legislación Mexicana, tomo I. México, D. F.: VLR.

Instituto Nacional de Administración Pública (1999). La Organización de la Administración Pública en México. México, D. F.: Limusa.

Gaceta de la Comisión Nacionalde Derechos Humanos (1997). Recomendación 90/97”. México, D. F.: $\mathrm{CNDH}$.

Gaceta de la Comisión Nacional de Derechos Humanos (2006). Recomendación 004/2006. México, D. F.: CNDH.

Gaceta de la Comisión Nacional de Derechos Humanos, Recomendación 50/97” (1997). México, D. F.: CNDH.

Gaceta Oficialdel Distrito Federalel 14 de noviembre de (2007). "Ley de justicia para adolescentes". México, D. F.: Distrito Federal.

Las Reglas Minimas de las Naciones Unidas para la Administración de Justicia de Menores, "Reglas de Beijing”(1985). Adoptadas por las Organización de las Naciones Unidas el 29 de noviembre. New York: ONU.

Marín, G. (1999). Historia de las instituciones de tratamiento para menores infractores del D. F. México, D. F.: Comisión de Derechos Humanos.

Pampillo, J. P. (2008). Historia general del derecho. México, D. F.: Oxford University Press.

Reglas de las Naciones Unidas para la protección de los menores privados de la libertad, Resolución 45/113 (1991). Naciones Unidas. Asamblea General. Cuadragésimo quinto período de sesiones. Resolución aprobada por la Asamblea General 2 de abril.

Reyes, L. A. (2007). La Administración de justicia del menor en prospectiva, México, D. F.: Fontamara.

Soberanes, J. L. (1997). Memorias de la Secretaría de Justicia. México, D. F.: Unam.

\section{Referencia:}

Ladislao Adrián Reyes y Juan de Dios González, "La genealogía de los niños de la calle y su educación en los Centros de Internamiento en México", Revista Latinoamericana de Ciencias Sociales, Niñez y Juventud, Manizales, Doctorado en Ciencias Sociales, Niñez y Juventud del Centro de Estudios Avanzados en Niñez y Juventud de la Universidad de Manizales y el Cinde, vol. 8, núm. 2, (juliodiciembre), 2010, pp. $1039-1050$.

Se autoriza la reproducción del articulo, para fines no comerciales, citando la fuente y los créditos de los autores. 